\title{
COMUNICACIÓN, EDUCACIÓN Y CULTURA DE PAZ
}

Lourdes Vera Alvarado*

Ivera@lasallep.mx

Edith Cortés Romero, Natalia Vázquez González, Guillermina Díaz Pérez y Javier Arzuaga Magnoni

Universidad Autónoma del Estado de México

2008

Ubicando una reflexión académica sobre las características, discrepancias, carencias y propuestas del enfoque democrático de las instituciones educativas en torno a la paz, la presente obra plantea un análisis sobre educación, comunicación y cultura, aspectos que establecen la recopilación de ensayos de diversos autores, se aborda como eje fundamental a tratar la paz y la visión de la democracia como una posibilidad de transformación social.

Observamos que en la mayoría de las conferencias, los autores dejan claro que es imposible promover la paz cuando existe falta de reconocimiento de la experiencia de la sociedad, identificación e involucramiento de cada acción que ataque el problema clave del conflicto y los actos de violencia que merman la historia social cada vez con mayor impacto.

El reto consiste en educar con valores para que las personas tengan la responsabilidad de trazar su propia historia, con instrumentos de transformación política y social que no impliquen la destrucción, intransigencia, odio y exclusión.

La educación para la paz hace una invitación a la acción que comienza a partir de la reflexión y comportamiento consciente que no existe una distancia entre educar y conocer, porque finalmente la historia es la búsqueda de una convivencia humana más equitativa y armónica donde se refuerce el sentimiento grupal y de comunidad, se desarrollen las capacidades, toma de decisiones y resolución no violenta de los conflictos.

La educación comienza por la convivencia, la cual finalmente se encuentra sustentada en los derechos humanos, el respeto, el diálogo, la solidaridad, la no violencia, el laicismo y la aceptación de la diversidad cultural.

El libro nos lleva a proponer un diálogo civilizado para entender más allá de un significado empírico lo que conlleva actualmente el vocablo paz desde un escenario implícito en el ámbito educativo y social. La clave que resaltan los escritores es la comunicación, aquella que surja de una efectiva retroalimentación en donde las partes expongan conjuntamente sus opiniones de forma pacífica sin violentar absolutamente hechos o fenómenos que día a día va construyendo la historia. 
Debemos entender esa comunicación desde un panorama amplio sin prejuicios humanos, sin convicciones ni exigencias gubernamentales y coercitivas, simplemente comprender a los demás, evitando el juicio moral al que se unan deseos de crecimiento verdaderamente humanos basados en valores reales y prácticos.

Es así como favoreciendo la participación de investigadores y analistas sociales; el libro ofrece un espacio para la difusión de las ideas e investigaciones encaminadas a la búsqueda de soluciones más allá de un factor retórico del tema sobre la cultura de paz, violencia y desarrollo. Para indagar las posibilidades históricas de un movimiento pacifista mexicano, en principio se abordan aspectos teóricos; enseguida se presenta un panorama de la paz y finalmente se realizan reflexiones teórico-metodológicas. 